\title{
Art and Science in Franz Marc's Animal Iconography
}

\author{
Eleni Gemtou
}

Professor, Dept. of Philosophy and History of Science, University of Athens, Panepistemioupolis 157 71, Athens, Greece.Email: egemtos@phs.uoa.gr

Received May 24, 2016; Revised July 10, 2016; Accepted July 15, 2016; Published August 18, 2016

\begin{abstract}
There has been a theory claiming that innovative artists have always created the appropriate atmosphere for forthcoming scientists to develop important hypotheses about the world. In this paper, the animal iconography of Franz Marc is discussed under the perspective of the achievements of modern ethology and its modified anthropomorphic approaches to animals that seem to have much in common with the empathetic attitudes of Marc, as shown both in his written texts and artworks. The basic argument presented is, however, that despite the interactions between art and science during history, it is of great importance to understand them as discrete rational fields with their own methods and expressive tools.
\end{abstract}

Keywords: Ethology, Franz Marc, Animal-Iconography, Art and Science

\section{Introduction}

According to a contemporary hypothesis (Shlain 1991), artists have always created appropriate conditions for scientists to form their theories about the world. Art has not just been a lateral narration, but much more a powerful driving force behind every revolutionary scientific discovery [1]. The invention of perspective at the beginning of the Quattrocento, for instance, created the appropriate atmosphere that led to the discovery of the elliptical orbits of the planets by the German astronomer Johannes Kepler 300 years later (Shlain 1991, 64-68). This theory is based on the acceptance that artists have an intuitive feeling that allows them to foresee situations playing an important role in the future [2].

Animals had been the subject matter of painting centuries before they began to interest scientists. They were however mostly complemental elements in landscapes, genres or even religious scenes. Animal painters have been known since the Renaissance as specialists in the portrayal of animals, many of whom, especially in the 17th century, collaborated with other artists in order to fill in their mythological scenes, for instance, with the presence of an animal. In the Dutch Golden Age there were smaller genre paintings produced by animal specialists, whose main interest was the descriptive depiction of animals. Despite the fact that such paintings belonged to the lowest scale in the hierarchy of genres, they were still very popular amongst royal and aristocratic patrons. From the 18th century, England became an important center for the production of portraits of racehorses, while French artists connected animal subjects with their decorative capriccios often set around garden statuary. In modern and contemporary eras animal

(c) AesthetixMS 2016. This Open Access article is published under a Creative Commons Attribution Non-Commercial 4.0 International License (http://creativecommons.org/licenses/by-nc/4.o/), which permits non-commercial re-use, distribution, and reproduction in any medium, provided the original work is properly cited. For citation use the DOI. For commercial re-use, please contact editor@rupkatha.com. 
painting has been reduced, while those practicing it have been mainly fascinated by wild life subjects.

However, Franz Marc (1880-1916), a painter mainly associated with the movement of German Expressionism, dedicated the whole of his quite short career to depicting animals, both wild and domestic, by investigating their psychological situation in an empathetic [3] manner. His approach to animals was not descriptive or allegorical, but an experiential and mentalist one, as he tried to understand their feelings by putting himself in their souls. This paper aims to form a new interpretative approach to Franz Marc's animal iconography by examining it in the framework of the developments in the field of ethology. My goal is to show that Marc's intentions had much more in common with the basic principles of modern anthropomorphism and its modified forms as they were developed from the 1970s in the framework of "critical anthropomorphism", "animal-centered anthropomorphism", "biocentric anthropomorphism" and "theromorphism" [4].

First, the development of the research into animal consciousness from the second half of the $19^{\text {th }}$ cen. up to our contemporary era (part 2) will be presented. Based on Marc's writings and paintings, as well as on Lipps's and Worringer's theories on empathy, there will be made some interpretative approaches to Franz Marc's animal iconography by comparing it with the theories of modern ethology (part 3). The aim of this paper is to show that Marc's animal paintings are another example-landmark to verify the theory that often artists have paved the way for scientists to form theories by making at an earlier chronical stage fresh and innovative observations about the world and life. However, it will be argued that despite the creative and inspiring interactions during history between art and science, it is worth while to understand them as discrete rational activities with sometimes common goals, but always different working methods and results (part 4).

\section{From Lewes's anthropomorphism to its contemporary modifications}

George Herbert Lewes, a Victorian polymath, was the first person to use the term "anthropomorphism" in order to characterize our tendency to ascribe human qualities to animals [5]. Up to that point the word had a theological meaning referring to the religious praxis of giving human characteristics to God and angels. In his Sea-side Studies at Ilfracombe, Tenby, the Scilly Isles and Jersey (1860), Lewes claimed that the fact that we speak about the vision of mollusks (that according to him have only rudimentary sensitivity to light) is to be associated with our tendency to anthropomorphize, "which causes us to interpret the actions of animals according to the analogies of human nature" (385).

At the same time Darwin published his theory of evolution by natural selection in his On the origin of species by means of natural selection or the preservation of favored races in the struggle for life (1859) that showed similar mechanisms for the evolution of human and nonhuman animals and thus played a decisive role in restricting the traditional Cartesian beliefs that animals were machines governed by the same laws as inanimate matter. In 1871 Darwin published his The descent of man and selection in relation to sex, where he claimed that there were no fundamental differences between human and higher mammals in their mental faculties. However, he didn't extend this statement to mental similarities but gave much more emphasis to psychological factors, fundamental intuitions and some instincts like self-preservation, sexual love and the love of the mother for her new-born offspring, that he thought to be common between man and animals. Darwin noticed that human is capable of more rapid improvement, because of 
his power of speaking and handing down his acquired knowledge. Though language is also a quality of nonhuman species it is rather in a more simplistic form, such as the growling of dogs and all of their communicative noises.

The next scholar who created anthropomorphic analogies between human and nonhuman animals was George Romanes. In his Animal Intelligence (1883) Romanes argued that certain bodily actions are caused by particular mental states, a correlation that should be common for all species. However he added that although the analogy between man and higher animal species must be taken for granted, the same cannot be applied for the lower species. While for instance expressions of affection or rage must be the results of similar mental procedures in humans and apes, this is not the case for a bee or an ant, whose "mental states may be widely different from those of a man, and yet most probably the nearest conception that we can form of their true nature is that which we form by assimilating them to the pattern of the only mental states with which we are actually acquainted" (9-10).

The approach of the British ethologist and psychologist Conwy Lloyd Morgan was similar. He stated in his Introduction to Comparative Psychology (1894) that we can understand the physical reaction of animals only in terms of our mind, which he defined as "the key by which to read the brute mind". Despite his intention to restrict anthropomorphic approaches in comparative psychology by using empirical and objective methods, his theory still included folk psychological believes. (Miller 1962)

The first steps towards the establishment of animal psychology as an empirical science were made by the American Edward Thorndike. In his Animal Intelligence (1911), Thorndike used experimental methods to study animal behavior even though he couldn't always avoid describing them in anthropomorphic terms. The total rejection of anthropomorphism as a method of animal psychology is connected with John B. Watson (1913). His aim was to avoid "absurd" and subjective interpretation of the behavioral actions of animals that have no place in an empirical science. Since scientists cannot avoid the subjectivity of their consciousness when they try to understand and interpret animal behavior, they should restrict their method to an empirical framework.

In the 1930s a new scientific field, ethology, arose that aimed at the objective study of nonhuman species behavior, as it was to be observed in their natural habitats. This was one of its basic differences from the contemporary science of behavioral animal-psychology that studied animals mostly in vitro environments. The common principle ethology and behavioral psychology shared in these days was their aim to belong to the empirical scientific field, meaning that both rejected traditional anthropomorphic methods. Thus ethologists restricted their research to absolute observable facts and avoided any deductions that could include subjective influences. Niko Tinbergen, one of the founders of ethology, claimed in his The Study of Instinct (1951): "...because subjective phenomena cannot be observed objectively in animals, it is idle either to claim or to deny their existence".

The next major paradigm in the study of animal consciousness was established in the 1970s, when the methods of cognitive psychology were introduced in the investigation of nonhuman species behavior. The ethologist Donald Griffin used in his The Question of Animal Awareness (1976) the term "cognitive ethology" defining the new scientific field that aimed to reintroduce the former practice both of the ascribing of particular behavior to particular brain functions and of the comparing of human and animal mental experiences (3-4).

Griffin's theory triggered the reappearance of anthropomorphism, which was banned from psychological and ethological investigations as a subjective, unscientific and invalid approach to 
animal behavior. It was though a modified form of anthropomorphism that aimed to preserve the prevailing empirical profile of animal psychology and classical ethology. The central concept of all moderated forms of modern anthropomorphism was to combine empirical experimental methods with a kind of experiential-imaginal transfer of the spirit of the scientist to the consciousness of the animal. As Rivas and Burghardt (2002) pointed out, it is necessary "to put oneself in the animal's shoes" (11) in order to better understand their behavior. Burghardt spoke of a "critical anthropomorphism" as a method that aims to understand animal behavior by making analogies to relevant human behaviors, but at the same time it takes into account that animals also have private experiences that researchers are not able to understand by empathetic projections. "Animal-centered anthropomorphism" is another moderation of anthropomorphism by Frans de Waal (1999), who also suggests empathetic approaches to animal consciousness, though by retaining "high standards of replicability and scientific scrutiny" (274).

A positive position on anthropomorphism is also held by Mark Bekoff (200o), who thinks that due to such methods we are able to understand the feelings of animals that otherwise would not be accessible to us. He calls his theory "biocentric anthropomorphism" (867), which uses anthropomorphism as a strict scientific method having the subjective factors restricted due to the prevalence both of the empirical data and the decisive a priori position that animals have their own and unique mental experience: modern anthropomorphism is not a loose method of an uncontrolled projection of our consciousness to the consciousness of animals, but much more a scientific way of understanding it in the framework of controlled and strict approaches to it.

Finally, another approach to animals' consciousness is to be mentioned that is called "theromorphism" [4] (Timberlake 2002). It also aims at the understanding of animal behavior and feelings, but not through comparing them with ours: animal consciousness should be understood through the ways they perceive reality. Theromorphism is the opposite of anthropomorphism as it is a pure objective and empirical animal-centered method that uses thorough observation and experimentation in order to carry out conclusions. Imagination and mentalist transfer still play a role, but only at the stage of the creation of hypotheses that should next be tested through objective data.

\section{Animal-centered interpretative approaches to Franz Marc's paintings}

Franz Marc was a German painter and printmaker, as well as one of the founding members of the expressionistic movement "Der Blaue Reiter" together with Wassily Kandinsky and August Macke. He is mostly known for his animal iconography, which has been interpreted through many approaches, either in the framework of the mystical notions connected with German expressionism, or according to the historical and cultural background of its era with particular symbolical associations with the WWI (Levine 1976; Dober 2013).

Before meeting Kandinsky (1910), Marc first painted landscapes in an academic manner. After 1903 he was influenced by French impressionistic work, but during a trip to Paris in 1907 he encountered the work of Vincent van Gogh and largely adopted his style. Finally, in 1910 Marc joined the German expressionistic group "Neue Künstlervereinigung”, which he and Kandinsky however left one year later in order to form the group "Der blaue Reiter". As he had a great interest in Eastern philosophies and religions, Marc immediately found common ground with Kandinsky, who passionately believed that art should not have a descriptive character, but rather a spiritual one by revealing the inner world both of living and inanimate beings. Marc was also an enthusiastic supporter of the idea that nature was alive following mystic rhythms and forces that 
people cannot perceive due to the destructive influences of civilization on man's consciousness. Both Kandinsky and Marc believed that abstraction was the most appropriate way to depict these spiritual forces.

It is not peculiar that Marc, as an artist with such ideas, was from the beginning of his career interested in subject matters revealing the pantheistic character of nature. He largely showed a preference for the depiction of animals that he understood as "more beautiful, purer", while he saw man as "ugly" (Marc 1920). When he depicted people he preferred primitive ones, or even children and the mentally ill, who most of the time have been accompanied by animals depicted as equal beings to them [6].

Marc cultivated an empathetic approach to animals that grew through the years. Such approaches may be very common to us today, but at the beginning of the $20^{\text {th }}$ century the Cartesian beliefs about the machinist and consciousness character of animals must have prevailed by influencing thoughts and behaviors. Marc's particular attitude towards animals must have been developed through many parameters and influences arrived at from both his own life experiences and the proceedings in contemporary science. He was familiar with animal iconography from his childhood up, as his father, Wilhelm Marc, was a professor at the Munich Academy specialized in animal and genre scenes. His approaches though were very different from those of his son, as he used to sentimentalize nature and anthropomorphize animal behavior in a more direct manner (Simmons 2014, 9). After the age of fourteen, Franz Marc also had immediate experiences with animals, especially horses and cows, of which he took care during his work on the farm of Hans and Lina Muller every summer (1894-1913) (Carey 2012, 15)

Marc was also subject to influences for the development of his empathetic attitude towards animals from the field of experimental psychology, in particular from the writings of Th. Lipps and W. Worringer. Animal studies were, at the beginning of the $2 \mathrm{O}^{\text {th }}$ cen., restricted and, as shown in part (2.), biases still prevailed that perceived animals as having brute minds that could be understood only through anthropomorphic approaches. Empathy was a new term at this time emerging from the experimental laboratory of Theodor Lipps founded in 1894 in the Psychological Institute at the University of Munich. It was initially used to define the way people perceive and understand reality by projecting their own morphological and psychical characteristics on all of its parts, whether they are living or material beings. In 1897 Lipps published a study on spatial perception, in which he developed an aesthetic theory based on the principle of pleasure and empathy. He explained aesthetic satisfaction as the result of the empathy felt by the spectator of an artwork: when we enjoy an artwork thereby gaining aesthetic pleasure, we unconsciously project our own external and internal characteristics on it. According to Lipps, humans are basically narcissistic and thus the act of loving an artwork reflects the fact that one loves himself.

In 1908 the art historian and follower of Lipps, Wilhelm Worringer, published his Ph.D. dissertation, Abstraction and Empathy, in which he had tried to connect empathetic procedures of understanding the world with the changing of styles in the development of art through its history. According to this theory, artistic creation was the result of two distinct types of approaching and perceiving reality, empathy and abstraction. Empathy worked for societies that felt themselves to be a part of the organic world, which they depicted through naturalistic approaches. This was the case of the Greek, the Roman and the Renaissance civilizations. On the other hand abstraction stood as the main expressive means for cultures that were not able to feel psychologically connected to the outside world that was perceived rather both as fractured and as a farrago of uncanny phenomena. From this point of view Worringer interpreted the Nordic animal style of the first millennium A.D. (Simmons 2014, 6-8). 


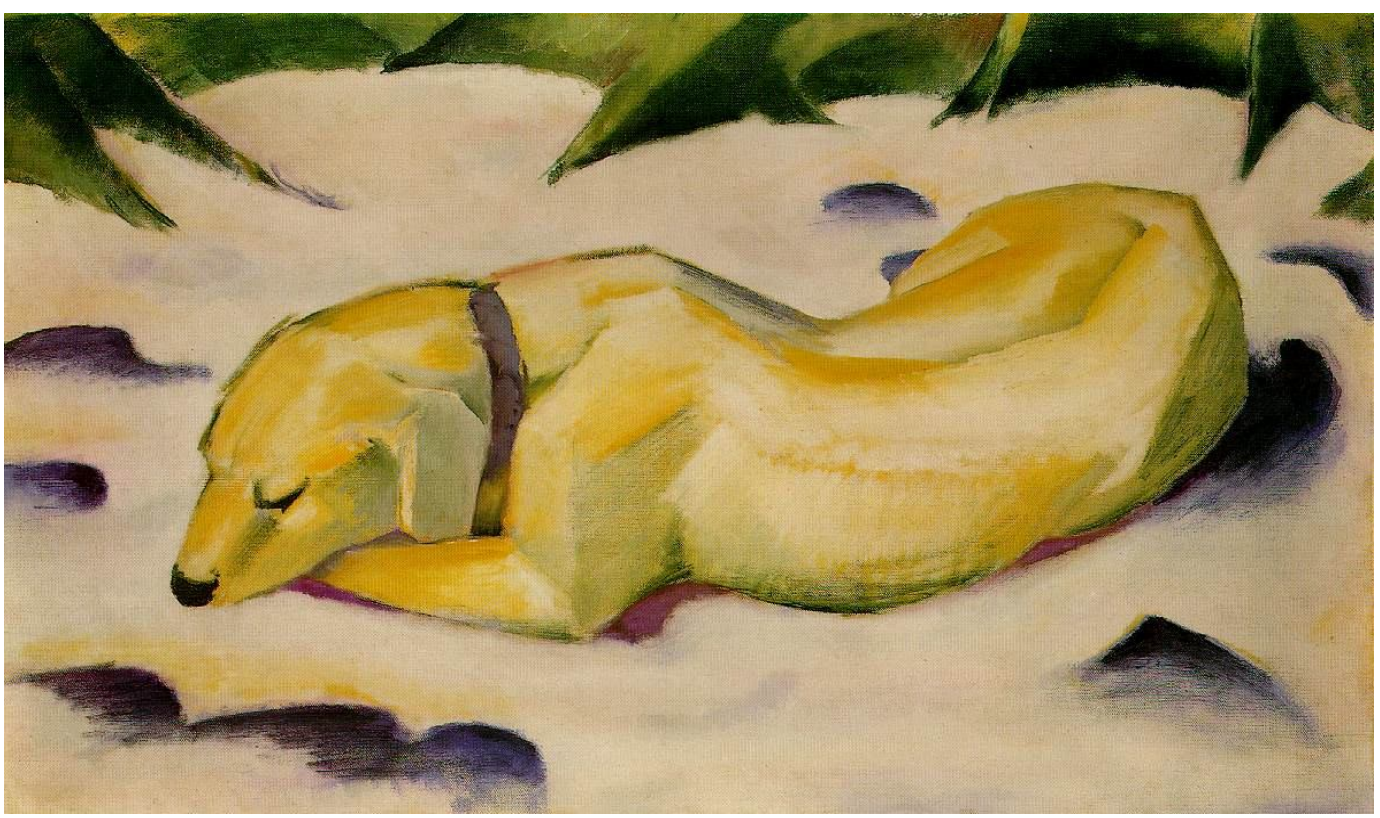

Fig. 1. Franz Marc, Dog Lying in the Snow, Oil on canvas, 62.5 x 105 cm, Stadelsches Kunstinstitut, Frankfurt, 1910-11

Marc combined in his work empathy and abstraction: he tried to understand the animals' feelings by using his knowledge, experience and intuition. In paintings depicting animals in calm situations, he used quite naturalistic and recognizable forms (fig.1). When he, however, represented anxious or frightened animals, he used abstractive means to express their negative and insecure respond to the world (fig.3). The abstract and cleaved surroundings in many animal paintings of Marc may be interpreted in the framework of Worringer's theory as an anthropomorphic approach of his to the animals' perception. Animals that feel insecure due to surrounding wild physical phenomena perceive reality more through abstract and confused forms, like the Germans who - according to Worringer - developed an abstract art due to their insecure psychological attitude throughout the world. Moreover Lipps's experiments had shown that abstract properties of objects responded to several feelings from joy and happiness to sorrow and anxiety. Thus, in the framework of empathetic and anthropomorphized efforts to understand the feelings of animals, the same perceptive principles are also to be applied to them: different grades of colors and different types of abstract shapes are to be identified with discrete animals' feelings.

Up to this point and according to the above analyzed influences and interpretative approaches to Marc's animal iconography, we can say that Marc painted animals in the framework of his pantheistic approaches to nature [7], because he perceived them as the purest living beings. He tried to understand their consciousness by projecting human psychological characteristics on them. Thus he depicted abstract and moving forms around them as corresponding to their feelings: in paintings with animals in calm and peaceful positions these abstract forms are wider, discrete and light colored. Otherwise, in paintings depicting physical events causing anxiety feelings, the abstract forms become sphenoid, spicated, complicated and darker.

The above described procedure of Marc to understand animals' consciousness is, though, not the complete one, as he took a further and significant step that made him a precursor of modern modified anthropomorphic methods of ethology. As shown in part (2.) ethology emerged 
as a strict empirical science in the 1930 s that rejected any anthropomorphic approach to animal consciousness as subjective and unscientific. In the 1970s though and in the framework of modern ethology, there has been a renewed approach to anthropomorphism as an avoidable method to create a path to the animals' inner world. The basic difference from the classic anthropomorphic approaches of the past, was the volition to combine mentalist approaches with objectivity: after the researcher had projected his consciousness onto the animal's, he used strict empirical data to confirm his/her hypothesis. That means that helshe built a picture of the animal's feelings by trying to see the world through its own (and not his/her) eyes.

This is that what Franz Marc did many decades ago. He created an animal iconography that was totally indifferent to "the type of the horses. The viewer should feel instead the inner, pulsing life of the animal" (Pipper 1910, 190). Beside this comment in Pipper's, The Animal in Art (1910), Marc has left some more manuscripts that show his goal of investigating animals' feelings by trying to see the world through their own eyes: "Can anything be more inscrutable for an artist than to imagine how an animal sees nature? How does a horse look at the world - an eagle, a deer, a dog? What a poverty-stricken idea, what a soulless convention, to put an animal in a landscape as we see it, when, by submerging ourselves in the soul of the animal, we can divine its own visual horizons" (Marc 1920, 99). In the same text Marc mentions that there are contemporary artists, like Kandinsky and Picasso, who project their inner world when depicting nature, others who approach it in a descriptive manner and capture it as it visually seems to be, and finally there is he who wants to paint the "predicate" that he explains as the world seeing through the animal's eyes.

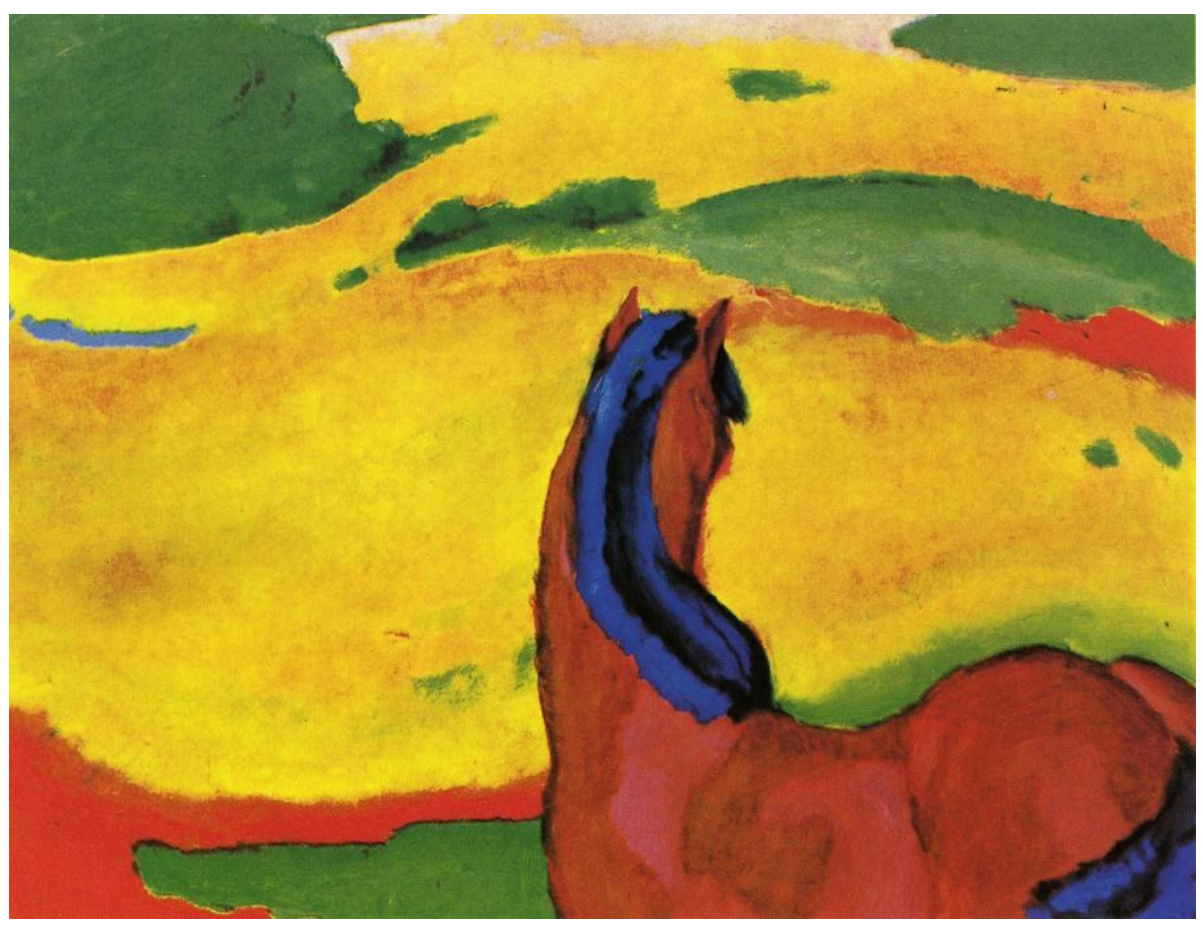

Fig. 2. Franz Marc, Horse in a Landscape, Oil on Canvas, 85 X 112 cm, Museum Folkwang, Essen, 1910

A nice case to understand Marc's above mentioned goal is his painting Horse in a Landscape (1910) (Fig.2), particularly in the way it has been analyzed by the behavioral scientist Klaus Zeeb in the catalogue for the exhibition "Franz Marc. Horses" in Boston (Zeeb 29 Sept.2000 -18 March 2001, 257-66). A horse is depicted from its back in the lower right corner of the picture, looking to a field that lies in front of it, covering in a curved and panoramic manner the whole surface. 
According to Zeeb, this is the way a horse perceives what it sees due to the place of its eyes in combination with its movable ears and sensitive nostrils. Thus Marc depicts the horse by trying to understand its awareness, not just by projecting his own way of seeing to it, but by seeing around through its own eyes.

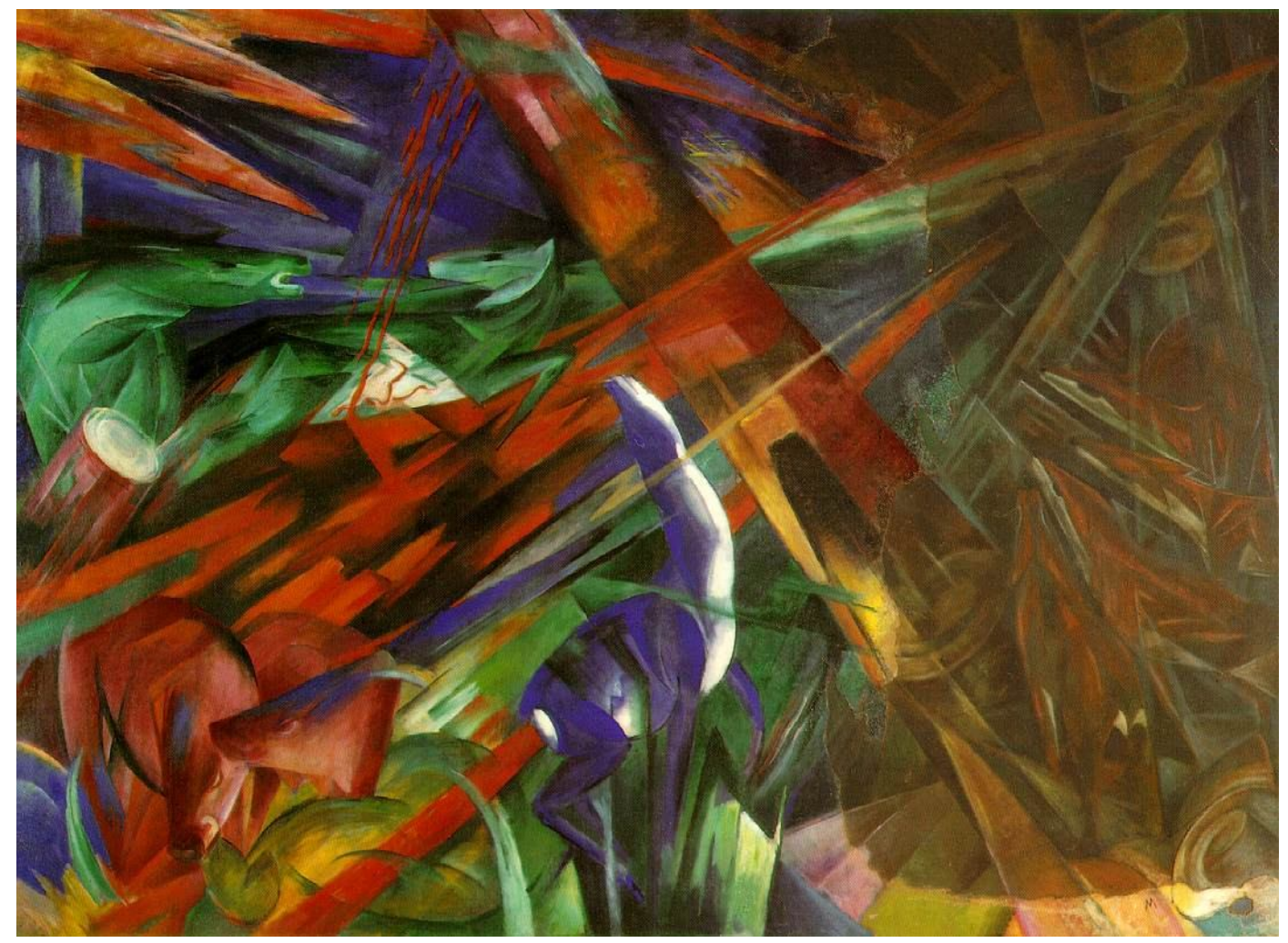

Fig. 3. Franz Marc, The Fate of the Animals, Oil on Canvas, 196 x 266 cm, Kunstmuseum Basel, 1913

The same can be claimed about other paintings, even if there is not a valid existing scientific theory to be applied to the interpretation. However Marc's own writings have been often very helpful in order to interpret the works in a way that follows the basic principles of modern ethology. A good example that shows Marc's effort to understand all kinds of animals' feelings and agonies through their own eyes is The Fate of the Animals (1913) (Fig. 3). As the forest is burning, the animals living in it feel the disaster coming and try to escape. They are overwhelmed by unspeakable fear and anguish, feelings that are expressed both through their eyes and movements and through the abstract forms of cones and kingpins abruptly mixed in the surrounding space. It is additionally to be mentioned that different interpretations of this painting prevailing in literature do not invalidate an interpretative approach from an ethological perspective, nor does the above interpretation aim to cancel other kinds of interpretative approaches. The most popular in the last years are those that connect its subject matter with the forthcoming WWI (Levine 1976, 269-277), of which Franz Marc was himself a victim. He fell dead on 4 March 1916, killed by a piece of shrapnel from a shell blast at the age of 36 .

\section{Art and Science in the work of Franz Marc}

The hypothesis that innovative artists have anticipated scientific theories has turned out in the last decades to be a very fashionable one. The notion, however, that the development of art is not 
an independent procedure as it is to be understood in relation to the development of other rational and religious systems of each era, is not a new one: many scholars have spoken about the Zeitgeist that triggers changes in all aspects of life. Art, though, as the cultural field preparing both the scientific community and the collective consciousness to create and to accept retrospectively new conceptions of reality, was first represented by Leonard Shlain, in his book Art and Physic: Parallel Visions in Space, Time E Light (1991)

Shlain claimed that "the radical innovations of art embody the preverbal stages of new concepts that will eventually change a civilization. Whether for an infant or a society on the verge of change, a new way to think about reality begins with the assimilation of unfamiliar images. This collation leads to abstract ideas that only later give rise to a descriptive language" (17). In the framework of this hypothesis, Shlain described the work of Galileo as consequential of the invention of linear perspective by Giotto and Alberti, the Newtonian theories as previously prepared by the work of Leonardo da Vinci, as well as the Einsteinian theory of spacetime as the aftermath of the visual experiments on space and time by Manet and Monet retrospectively.

This is an interesting theory that is though only partially true, as Shlain makes huge time leaps thereby avoiding to show that, during periods which he fails to represent, enormous changes happened in the sciences that gradually led to the creation of the examined theories (Scaruffi 2006). Nevertheless it seems that indeed artists, due to their strongly observational and intuitive characteristics, have been capable of expressing, either in a verbal or non-verbal manner, statements about the world contributing to the formation of the appropriate rational circumstances for the upcoming major paradigms in science. This does not however cancel the significant role played by the inner developments of the scientific system in itself.

Nevertheless this admission does not imply that artists have been scientists, as has been claimed more than once in literature. Jonah Lehrer (2008) has, for instance, asserted that Proust was a neuroscientist himself, due to his novel Remembrance of Things Past (1913-1927) and its famous passage in the first of its seven volumes that describes the act of tasting a madeleine by his semi-autobiographical narrator that evoked in him an entire ensemble of childhood memories. Lehrer compares Proust's statements with the research done in the Kandel lab both on the molecular mechanisms playing a decisive role in the formation of memory and on the stimuli that may reactivate it.

In the same spirit Jean Carey (2012) claims that Franz Marc was an ethologist, because of his volition to look inside animals and understand their consciousness by passing over the pure anthropomorphic approaches of the folk animal psychology of his time: Franz tried to see the world through the animals' own eyes. As shown in part (2.) this has been indeed the goal of modern ethology, as it has appeared through its several modifications since the 1970s. Moreover Carey's argument is based on J. M. Coetzee's initiative, when he was invited to give a lecture at Princeton on 15 and 16 October 1997, as part of the Tanner Lectures on Human Values, to narrate the short novel by Franz Kafka Report to an Academy, in which the ape Red Peter himself presents a paper to scholars by describing both the cruel experiments done on him and the feelings of loneliness and isolation he is tortured by. According to Coetzee, speaking through his alter ego Elisabeth Costello, Kafka was a much better observer of the inner life of apes than the scientists studying them at the same time (Carey 2012, 9).

The question arising is, if common goals and methods are sufficient requirements to recognize a person as a scientist, even if he/she is working in the field of the arts. It is of great importance, due both to a systematical arrangement of knowledge and a correct rating of its validity, to keep strict limits between art and science. An artist cannot become a scientist just 
because he makes thorough observations, which he/she expresses in an artistic verbal or nonverbal language. The fact that contemporary artists are used to working in labs together with scientists by doing experiments and producing innovative results (Wilson 2012) does not render them scientists: they are still artists and their work, independently from the fact that it is a result of experimental processes, is still an artistic one aiming both at aesthetic pleasure and at the renewal of the ways we perceive reality in a subjective manner. Under this perspective, Franz Marc indeed paved the way for the forthcoming ethological theories, but he has always been an artist, a great one, as he managed to influence to a certain degree the public's mind.

\section{Notes}

1. L. Shlain (1991) recognized a close connection between revolutionary art and the forthcoming scientific discoveries. There have been, however, many art critics before him, who understood the avant-garde art of each era as preparing people for the future. Robert Hughes (1980, 366), for instance, claims: "The essence of avant-garde myth is that the artist is a precursor; the truly significant work of art is the one that prepares the future."

2. Shlain (1991, 18) notices: "I shall examine art ... as a Distant Early Warning system of the collective thinking of a society. Visionary art alerts the other members that a conceptual shift is about to occur in the thought system used to perceive the world". He also quotes the words of the art critic John Russel $(1974,271)$ : "There is in art a clairvoyance for which we have not yet found a name, and still less an explanation".

3. Empathy is the ability to understand another being's feelings and thoughts by trying to perceive them from within his/her frame of reference.

4. The term is used as such by W.Timberlake (2002, 105-114). However, the correct term would be "theriomorhism" that is constructed by the Greek words "therion" (meaning animal) and "morphe" (meaning form). The term is used in contradistinction to the term "anthropomorphism" to characterize animal-centered observations.

5. For a brief but comprehensive history of the approaches to anthropomorphism in comparative psychology and ethology, see Wynne (2007). For a critic to contemporary uses of anthropomorphism, see pp. 131-132.

6. Marc depicted humans only between 1910-12, as parts of Arcadian landscapes, in which humans were naked and involved with dynamic physical phenomena and other non- human animals (Simmons 2014, 12-14)

7. Marc saw animals as parts of "animalized" nature that means of a living nature. The same applies for his art that he called "animalizing art" (Piper 1910, 190). In a letter to Macke, Marc mentions: "...The animalization of art connects soul and corporeality. Anima and animal are, like man and wife, reconciled, like in Paradise, in the painting..." (Dering and Jochimsen 1997, 38-39)

\section{References}

Bekoff, M. (2000). Animal Emotions: Exploring Passionate Natures. Bioscience, 50, 861-870

Carey, J. (2012). Franz Marc as an Ethologist. In Social Science Research Network. http://papers.ssrn.com/sol3/papers.cfm?abstract id=2648753 (retrieved 15/5/2016)

Darwin, C. (1859). On the Origin of Species by Means of Natural Selection or the Preservation of Favored Races in the Struggle for Life. London: John Murray

Dering, P. and Jochimsen, M. (1997). August Macke in Tegernsee. Bonn: Verein August Macke Haus

De Wall, F. (1999). “Anthropomorphism Anthropodenial: Consistency in our Thinking about Humans and other Animals". Philosophical Topics, 27, 255-280 
Dober, M. (2013). Franz Marc: Utopian Hopes for Art and the Great War. Overland. https://overland.org.au/2013/o4/franz-marc-utopian-hopes-for-art-and-the-great-war (retrieved 10/5/2016)

Griffin, D.R. (1976). The Question of Animal Awareness: Evolutionary Continuity of Mental Experience. New York: Rockefeller University Press

Hughes, R. (1980). The Shock of the New. New York: Alfred A. Knopf

Lehrer, J. (2008). Proust was a Neuroscientist, USA: Mariner books

Levine, Fr. S. (1976). The Iconography of Franz Marc's Fate of Animals, The Art Bulletin, vol.58, No.2, 269277

Lewes, G. H. (1860). Sea-side Studies at Ilfracombe, Tenby, the Scilly Isles and Jersey ( $2^{\text {nd }}$ ed.). Edinburgh: William Blackwood \& Sons

Lipps, Th. (1897). Raumaesthetik und Geometrisch Optische Täuschungen. Leipzig: Johann Ambrosius Barth

Marc, Fr. (1920). Briefe, Aufzeichnungen und Aphorismen. Berlin: P.Cassirer

Miller, G.A. (1962). Psychology, the Science of Mental Life. New York: Harper \& Row

Morgan, C. L. (1894). Introduction to Comparative Psychology. London: Walter Scott Ltd.

Piper, R. (1910). Das Tier in der Kunst. Munich: R.Piper

Rivas, J. \& Burghardt, G.M. (2002). Crotalomorphism: A Metaphor for Understanding Anthropomorphism by Omission. In M. Bekoff, C.Allen \& G.M. Burghardt (Ed.), The Cognitive Animal: Experimental and Theoretical Perspectives of Animal Cognition. Cambridge: MIT Press

Romanes, G. (1883). Animal Intelligence. New York: D. Appleton \& Co

Russel, J. (1974). The meanings of Modern Art. New York: Harper \& Row

Scaruffi, P. (2006). Leonard Shlain: Art and Physics. http://www.scaruffi.com/mind/shlainz.html (retrieved $15 / 5 / 2016)$

Shlain, L. (1991). Art and Physics. Parallel Visions in Space, Time \& Light. USA: Perennial

Simmons, W. S. (2014). Abstraction and Empathy on the Eve of World War I. Konturen. Vol 5

Thorndike, E.L. (1911). Animal Intelligence: Experimental Studies. New York: Macmillan

Timberlake, W. (2002). Constructing Animal Condition. In, The Cognitive Animal: Empirical and Theoretical Perspectives on Animal Cognition. M. Bekoff, C. Allen, G M. Burghardt (Ed.), Cambridge: MIT Press

Tinbergen, N. (1951). The Study of Instinct. Oxford: Oxford University Press

Watson, J. B. (1913). Psychology as the Behaviorist views it. Psychological Review, 20, 158-177.

Wilson, St. (2012). Art and Science. How Scientific Research and Technological Innovation are becoming Key to $21^{\text {st }}$ century aesthetics. London: Thames \& Hudson

Wynne Clive D.L. (2007). What are Animals? Why Anthropomorphism is still not a Scientific Approach to Behavior. Comparative Cognition \& Behavior Reviews, vol.2, 125-135

Worringer, W. (1997). Abstraction and Empathy: A Contribution to the Psychology of Style. Chicago: Elephant Paperbacks

Zeeb, Kl. (29 Sept. 2000 - 18 March 2001). The Horse as a Living Creature: Franz Marc's Horses in the Eyes of a Behavioral Scientist. In, Franz Marc. Horses. Chr. Von Holst (Ed.). 257-266. 